\title{
Compact Airborne Spectrographic Imager (CASI) used for mapping biophysical parameters of boreal forests
}

\author{
Jing M. Chen, ${ }^{1}$ Sylvain G. Leblanc, ${ }^{1}$ John R. Miller, ${ }^{2}$ Jim Freemantle, ${ }^{3}$ \\ Sara E. Loechel, ${ }^{4}$ Charles L. Walthall, ${ }^{5}$ Kris A. Innanen, ${ }^{2}$ and H. Peter White ${ }^{2}$
}

\begin{abstract}
During the Boreal Ecosystem-Atmosphere Study (BOREAS), which took place in Saskatchewan and Manitoba in 1994, the Compact Airborne Spectrographic Imager (CASI) acquired images of boreal forests. In this paper we present results of radiometric and geometric analysis of the CASI data for developing algorithms for retrieving leaf area index (LAI) and crown closure of the boreal forest. The images of over 30 sites, composed of black spruce, jack pine, and aspen stands, were acquired on different days and locations with various solar illumination and view geometries. The geometrical-optical model, named "4-Scale" [Chen and Leblanc, 1997, 1316-1337], was used to correct the images to a common solar zenith angle $\left(35^{\circ}\right)$ and a common view angle (nadir). The 4-Scale model is also used for radiometric analysis based on spectral signatures of leaves and the background (moss, grass, and soil) acquired using various field and laboratory techniques. The red reflectance of all three cover types decreased with increasing LAI as expected. Similar but weaker decreasing trends were found in the near-infrared (NIR) band for conifer stands in contrast to previous findings for cropland and grassland. No significant NIR response to LAI was found for aspen stands. It is shown from 4-Scale that as LAI increases, the crown and ground shadow fractions of conifer forests increase, while the sunlit background fraction decreases and the sunlit crown fraction increases. The large change in the shadow fractions is the major factor controlling the behavior of red and NIR signals. Since boreal forests have abundant green moss and understory as the background, there is only a small difference in optical properties between the overstory and the background. The increases in the shadow fractions with LAI help strengthen the response of optical measurements to changes in LAI, providing a key mechanism for remote information retrieval. The implications of these findings on formulating/selecting vegetation indices and inversion models are discussed in this paper. Relationships of crown closure with CASI measurements are also included in the analysis.
\end{abstract}

\section{Introduction}

Leaf area index (LAI) is one of several biophysical parameters that can be mapped using digital remote sensing techniques. It is therefore often used as a basic vegetation structural parameter to scale up stand-level measurements of various energy and mass fluxes to a region [Sellers et al., 1992; Liu et al., 1997]. Satellite digital imagery has been demonstrated to be useful for LAI retrieval [Badhwar et al., 1986; Peterson et al., 1987; Nemani et al., 1993; Spanner et al., 1994; Hall et al., 1997; Chen and Cihlar, 1996] and has been used for regional LAI mapping [Liu et al., 1997; Cihlar et al., 1997]. In the algorithm development using satellite data, uncertainties and errors are often encountered due to image registration, atmospheric correction, date matching between imaging and

\footnotetext{
${ }^{1}$ Canada Centre for Remote Sensing, Ottawa, Ontario.

${ }^{2}$ Department of Physics and Astronomy, York University, Toronto, Ontario.

${ }^{3}$ Centre for Research in Earth and Space Technology, Toronto, Ontario.

${ }^{4}$ Department of Geography, University of Maryland, College Park.

${ }^{5}$ Remote Sensing and Modeling Laboratory, ARS-USDA, Beltsville, Maryland.

Copyright 1999 by the American Geophysical Union.

Paper number 1999JD900098.

0148-0227/99/1999JD900098\$09.00
}

ground measurements, and insufficient spatial resolution to resolve surface heterogeneity. Many of these problems can be overcome when airborne remote sensing techniques are used. Early studies have shown the usefulness of airborne optical sensors for LAI mapping [Curren and Williamson, 1987; Gong et al., 1992; Wulder et al., 1996]. The Compact Airborne Spectrographic Imager (CASI), which was developed for various land and aquatic applications [Anger et al., 1994], was used to acquire a large number of images over forests during the Boreal Ecosystem-Atmosphere Study (BOREAS) field campaigns in 1994 [Miller et al., 1995]. We therefore examined these airborne data for the purpose of improving our algorithms used for LAI mapping for the BOREAS region and the boreal forest in general.

Previously, BOREAS ground measurements of LAI were correlated with Landsat thematic mapper (TM) data for conifer species [Chen and Cihlar, 1996], and the algorithms were applied to AVHRR data to obtain LAI images of the BOREAS region in Saskatchewan and Manitoba, Canada [Cihlar et al., 1997]. The sensitivity of vegetation indices, including the normalized difference vegetation index (NDVI) and the simple ratio (SR) formulated using red and nearinfrared (NIR) reflectances, was found to be small with changes in LAI. This small sensitivity conceivably results from the small difference between the spectral signatures of leaves [Middleton et al., 1997] and the background [Miller et al., 1997] 
consisting of green moss, lichen, herbaceous species, and plant litter. When the responses of red and NIR reflectances to increasing LAI are studied, Chen [1996a] found that the small sensitivity was caused by simultaneous decreases of the red and NIR reflectances with increasing LAI. The decrease in red reflectance is expected because red reflectance of overstory canopy is usually smaller than that of background. The behavior of NIR reflectance causes concern on the reliability of the data because it is generally conceived that NIR reflectance would increase with increasing LAI when the leaf NIR reflectance is larger than that of the background. There was considerable scatter of the available TM data points and the significant variability prevents further examination of the causes of the unusual NIR behavior. When BOREAS helicopter spectral data are analyzed against the same ground data set, Loechel et al. [1997] also found the similar behavior in the NIR band, strengthening this finding, but the scatter of data points was also considerable. CASI data therefore provide an opportunity to examine this problem, which is of fundamental interest in understanding optical remote sensing signals from forested surfaces in general.

Although errors in image registration and atmospheric corrections are considerably reduced using CASI data as compared with those using Landsat TM data, CASI data still show large variability when site averages obtained from images acquired at different times are compared to ground-based measurements of LAI. Much of the variation comes from changes in solar and view angles. It is therefore necessary to normalize the images to a common illumination-view geometry before any quantitative analysis. This geometric normalization is made using bidirectional reflectance distribution functions (BRDF) derived using the 4-Scale model [Chen and Leblanc, 1997]. It will be shown in this paper that after the BRDF corrections the uncertainty in the relationships between vegetation indices and LAI is reduced, and the unusual NIR behavior appears more distinctly. The 4-Scale model is also used to investigate the response of the individual bands to changes in LAI.

The purpose of this paper is to investigate the information content of optical remote sensing signals from boreal forests using reliable airborne digital images. The specific objectives of this paper are (1) to demonstrate the importance and methodology of making BRDF corrections to airborne images; (2) to simulate the observed airborne data using a radiative transfer model for the purpose of improving algorithms for biophysical parameter retrieval; (3) to derive separate LAI and crown closure algorithms for the major boreal tree species of black spruce, jack pine and aspen; and (4) to show an example LAI image over a black spruce site.

\section{CASI Image Acquisition and Processing}

The CASI sensor is a push-broom imager capable of flexible image collection in visible and near-infrared wavelength regions (400-950 nm) [Anger et al., 1994]. For the data used in this study the sensor was operated in the spatial mode in which multispectral images in 15 bands were collected by viewing in the nadir direction with band centers ranging from 409.7 to $905.4 \mathrm{~nm}$. The analysis presented here utilized band 7 (659.5$671.5 \mathrm{~nm})$ and band $13(794.7-804.9 \mathrm{~nm})$. For these data the sensor was flown at $\sim 125$ knots and an altitude of $1675 \mathrm{~m}$ above ground level with a $55 \mathrm{~ms}$ integration time, which yielded pixels of $2 \mathrm{~m} \times 4.4 \mathrm{~m}$ with an image swath of $1024 \mathrm{~m}$.
For more detailed information on the deployment of CASI at BOREAS and instrument calibration and processing procedure, see Miller et al. [1995] and Gray et al. [1997].

The CASI data collection at BOREAS was focused on the flux tower sites; image collection over the auxiliary sites was considered a second priority and therefore tended to occur later in the day (therefore at larger solar zenith angles) and perhaps somewhat poorer sky conditions (larger aerosol optical depths). This undoubtedly added to the variability observed in the data extracted for this study. Nevertheless, imagery was collected consistently in generally clear sky conditions (normally without cloud shadow in the imagery) and with the swath in the solar plane to minimize the across-track BRDF effects across the full $35^{\circ}$ angle range.

Raw CASI images were converted from digital number to spectral radiance using radiance scale factors determined by the Instrument Services Laboratory at CRESTech. The calibration procedure has been described by Gray et al. [1997]. Radiance images were converted to apparent surface BRF using a variation of the $5 \mathrm{~S}$ radiative transfer code called the Canadian advanced modified 5S (CAM5S) [O'Neill et al., 1996]. The atmospheric correction procedure uses CAM5S to produce a series of coefficients that allow conversion from at-sensor radiance to apparent surface bidirectional reflectance factor (BRF) for each pixel in the image. The procedure corrects for both sensor and solar geometry and allows for a number of background reflection options. For the purpose of this study, the background reflectance was assumed to be the same as the target pixel for each pixel in the image. The model requires an aerosol optical depth value at $550 \mathrm{~nm}$. This value was derived from the BOREAS database of Sun photometer readings. Extensive validation of the model results were carried out using known reflectance targets placed at the Prince Albert Airport. The absolute difference between the corrected and the measured surface BRF values were found to be about $0.7 \%$ in the visible and $1.3 \%$ in the near infrared during the July 1994 BOREAS field campaign [O'Neill et al., 1997]. During BOREAS in 1994, CASI images were acquired for several times during the intensive field campaigns (IFC-w, IFC-1, IFC-2, IFC-3) over forests of various types: black spruce, jack pine, aspen, and mixed wood. We chose CASI images acquired in early spring (IFC-1) in this study to minimize the background effect, following the recommendation of Chen and Cihlar [1996], who found that early spring TM data are better correlated with the overstory LAI than the summer data.

\section{Ground Measurements of LAI}

A database for all leaf area index measurements made during BOREAS was constructed. The techniques used include LAI-2000 and TRAC [Chen and Cihlar, 1996], hemispherical photography [Rich et al., 1995], and allometry [Gower et al., 1997]. A review of the techniques and the data set is given by Chen et al. [1997]. Briefly, either LAI-2000 or hemispherical photography provides a measure of the effective LAI, which is then converted into LAI using a foliage-clumping index derived from TRAC measurements and shoot sample analysis. The crown closure data were obtained from LAI-2000 gap fraction measurements in the first ring in the angle range from $0^{\circ}$ to $15^{\circ}$. A site is usually measured along two $50 \mathrm{~m}$ transects arranged in perpendicular lines. For some intensive sites (tower sites) the measurements were made on three $300 \mathrm{~m}$ transects. The sites are located in the BOREAS southern study 
area (SSA) near Candle Lake and Prince Albert, Saskatchewan, and in the northern study area (NSA) near Thompson, Manitoba.

\section{Bidirectional Reflectance Distribution Function (BRDF) Correction}

To facilitate quantitative comparisons between CASI images acquired at different Sun angles and between different pixels at different view angles within the same images, we used a canopy radiative transfer model, named 4-Scale [Chen and Leblanc, 1997], to normalize all images and pixels to the same geometry: solar zenith angle (SZA) at $35^{\circ}$ and nadir view. This is a geometric-optical model, which calculates reflectance at given wavelengths for various illumination and view angle combinations. It considers the effect of canopy architecture at the four major scales: tree groups, tree crowns, branches, and shoots (leaves for deciduous). Developed after the existing $\mathrm{Li}$ and Strahler's model, 4-Scale employs several new modeling methodologies: (1) the nonrandom spatial distribution of trees is simulated using the Neyman type-A distribution [Neyman, 1939] which creates patchiness of a forest stand; (2) inside the crowns, a branch architecture, defined by a single-branch inclination angle and an angle distribution of foliage elements (leaves for deciduous and shoots for conifers), is used to improve the calculations of beam and view line penetrations; (3) the hotspot is computed both on the ground and on the foliage based on gap size distributions between and inside the crowns, respectively; and (4) the imaginary tree crown surface is treated as a complex medium rather than a smooth surface, so shadowed foliage can be observed on the sunlit side and sunlit foliage can be observed on the shaded side. Canopy gap size distribution measurements made by TRAC [Chen and Cihlar, 1995] are used to validate the between-crown and within-crown gap size distributions calculated in the model. The mathematical descriptions of these main processes considered in the model have been linearized for image processing [Chen and Cihlar, 1997] and for inversion and other purposes [White et al., 1998]. The model uses several layers of input parameters for foliage and background optical properties (spectral reflectances for the sunlit components), basic canopy structural attributes (LAI, height, crown radius, stem density), advanced structural attributes (tree grouping factor, neighbor repulsion factor, branch architecture, shoot-level clumping factor, understory density, and structure), and sky spectral irradiance (bandspecific sky diffuse radiation fractions). A set of default values for all these parameters are given for the major boreal species (black spruce, jack pine, and aspen), so the model can be run without any modifications to obtain the first-order estimates. Without any field data the model can be used to investigate the sensitivity of optical measurements to any parameters under different combinations of others. With field data to replace the default values, the model accuracy can be improved. This is extremely useful for remote sensing algorithm development [Leblanc et al., 1997; Walthall et al., 1997]. In this study, the model is used as a tool for angular normalization. All default values [Chen and Leblanc, 1997; Leblanc et al., 1999] are used except that all basic canopy structural parameters are modified according to ancillary data or best estimates from LAI and location.

\section{Results}

Results of improved LAI and crown closure (CC) algorithms derived after BRDF corrections are shown below. The mechanisms controlling optical signals in the individual channels have been investigated using the 4-Scale model. An example LAI image over a BOREAS SSA old black spruce (SOBS) site is shown, and the methodology for high-resolution LAI mapping is discussed. Since SR is found to be more linearly related to LAI than NDVI [Chen, 1996a], only SR algorithms are shown in this paper.

\subsection{BRDF Corrections and Improved LAI and CC Algorithms}

CASI images were first stratified into three groups by cover types: black spruce, jack pine, and aspen. The mixed cover type is not included in this study because the number of sites is too few. Table 1 provides a summary of the site names (BOREAS standard), location, structural attributes (LAI and CC), solar and view zenith angles, difference between solar azimuth and CASI scan line, red and NIR reflectances, and BRDF correction factors. The correction factors for black spruce species are slightly different from those shown by Chen et al. [1998] because site-specific canopy structural parameters rather than the default values in the 4-Scale model were used in this study. The analysis of the data is then carried out by cover type and is shown in Figures 1-3 for LAI and Figure 4 for CC.

The response of the reflectance in red and near infrared (NIR) to changes in LAI for black spruce before BRDF correction is illustrated in Figures 1a and 1b, respectively. The scatter of the data points in Figures 1a and $1 \mathrm{~b}$ is considerable. The scatter arises from several sources: solar zenith angle variation, view zenith angle variation (some sites are close to the edge of the CASI image strip), the background variation, canopy architectural difference for the same LAI, etc. Because of the effects of these various factors, no significant trends of red and NIR reflectance with LAI changes can be reliably detected. The trends are enhanced after BRDF corrections, which removed the variability caused by the angular variations. Figures $1 \mathrm{~d}$ and $1 \mathrm{e}$ show the corresponding distributions after BRDF corrections. The attributes considered in the BRDF corrections are given in Table 1 . The BRDF correction factors shown in Table 1 normalize all reflectance to the standard geometry: solar zenith angle of $35^{\circ}$ and nadir view. Because of the combined effects of solar zenith angle and view zenith angle variations, the correction factors are very large and sometimes are even close to a factor of 2. The major changes that BRDF corrections made to the data are the different reflectance increases for the NSA sites when corrected from large SZAs to $35^{\circ}$. For open stands with low LAI values in NSA, the reflectances increase as the SZA decreases as a result of the decrease in shadow fractions. The increase in NIR is smaller than that in red because of the strong multiple scattering that reduces the dependence of NIR reflectance on SZA; that is, the shadow fractions in NIR are relatively brighter than those in red. Although the scatter of the data points is not much reduced after the BRDF corrections, the trends are more significantly determined, as seen in the increased $R^{2}$ values. Figures $1 \mathrm{~d}$ and $1 \mathrm{e}$ are similar to those shown by Chen [1996a], obtained from Landsat TM images without BRDF corrections, but better than them in terms of statistical significance. Although the two TM images used by Chen [1996a] were acquired near vertical view with only a small difference $\left(7.3^{\circ}\right)$ in solar zenith angle, part of the variability in 
Table 1. BOREAS Southern Study (SSA) and Northern Study Area (NSA) Black Spruce Site Parameters: Crown Closure (CC), Leaf Area Index (LAI), View Zenith Angle (VZA), Azimuthal Difference Between Sun and View Angle (PHI), Solar Zenith Angle (SZA), Uncorrected Reflectances, BRDF Correction Factors Obtained With 4-Scale, and Corrected Reflectance

\begin{tabular}{|c|c|c|c|c|c|c|c|c|c|c|c|c|c|c|c|c|}
\hline \multirow[b]{2}{*}{ Site } & \multirow[b]{2}{*}{ Species } & \multirow[b]{2}{*}{ Area } & \multirow[b]{2}{*}{1994} & \multirow[b]{2}{*}{ LON } & \multirow[b]{2}{*}{ LAT } & \multirow{2}{*}{$\begin{array}{l}\text { Crown } \\
\text { Closure }\end{array}$} & \multirow[b]{2}{*}{ LAI } & \multirow[b]{2}{*}{ VZA } & \multirow[b]{2}{*}{ PHI } & \multirow[b]{2}{*}{ SZA } & \multicolumn{2}{|c|}{ Reflectance } & \multicolumn{2}{|c|}{$\begin{array}{l}\text { BRDF } \\
\text { Correction }\end{array}$} & \multicolumn{2}{|c|}{$\begin{array}{l}\text { Corrected } \\
\text { Reflectance }\end{array}$} \\
\hline & & & & & & & & & & & RED & NIR & RED & NIR & RED & NIR \\
\hline $\mathrm{s} 8 \mathrm{w} 0 \mathrm{~s}$ & spruce & NSA & June 7 & -97.840 & 55.768 & 0.48 & 4.55 & 15.0 & 35.0 & 37.45 & 3.17 & 19.44 & 0.94 & 0.91 & 2.97 & 17.67 \\
\hline $\mathrm{t} 0 \mathrm{p} 7 \mathrm{~s}$ & spruce & NSA & June 6 & -98.823 & 55.884 & 0.10 & 2.84 & 7.5 & 105.0 & 55.43 & 1.58 & 12.13 & 1.81 & 1.51 & 2.87 & 18.26 \\
\hline $\mathrm{t} 3 \mathrm{u} 9 \mathrm{~s}$ & spruce & NSA & June 6 & -97.983 & 55.831 & 0.27 & 2.93 & 17.6 & 130.0 & 50.45 & 2.14 & 13.04 & 1.84 & 1.50 & 3.95 & 19.59 \\
\hline uss & spruce & NSA & June 6 & -97.993 & 55.839 & 0.52 & 4.27 & 12.0 & 50.0 & 50.45 & 2.03 & 17.16 & 1.49 & 1.28 & 3.03 & 21.93 \\
\hline qq7s & spruce & NSA & June 6 & -98.640 & 55.916 & 0.45 & 4.97 & 0.0 & 0.0 & 54.30 & 2.23 & 17.68 & 1.86 & 1.54 & 4.14 & 27.25 \\
\hline $6 \mathrm{t} 6 \mathrm{~s}$ & spruce & NSA & June 6 & -98.187 & 55.880 & & 1.70 & 0.0 & 0.0 & 51.56 & 3.85 & 19.18 & 1.33 & 1.25 & 5.11 & 24.01 \\
\hline $\mathrm{t} 7 \mathrm{t} 3 \mathrm{~s}$ & spruce & NSA & June 6 & -98.226 & 55.894 & & 2.90 & 2.6 & 145.0 & 51.54 & 3.67 & 18.82 & 1.57 & 1.39 & 5.78 & 26.15 \\
\hline $\mathrm{t} 8 \mathrm{~s} 4 \mathrm{~s}$ & spruce & NSA & June 6 & -98.371 & 55.917 & & 1.31 & 13.0 & 140.0 & 53.49 & 4.37 & 22.19 & 1.43 & 1.32 & 6.23 & 29.29 \\
\hline tf03 & spruce & NSA & June 6 & -98.481 & 55.880 & 0.47 & 4.27 & 3.0 & 95.0 & 33.26 & 3.03 & 18.71 & 0.98 & 0.97 & 2.96 & 18.17 \\
\hline $2 i 4 s$ & spruce & SSA & May 27 & -105.140 & 53.930 & 0.33 & 4.80 & 3.0 & 140.0 & 35.48 & 2.29 & 16.51 & 1.07 & 1.04 & 2.46 & 17.22 \\
\hline $6 \mathrm{k} 8 \mathrm{~s}$ & spruce & SSA & May 27 & -104.759 & 53.944 & 0.45 & 3.83 & 13.0 & 110.0 & 33.16 & 1.74 & 12.92 & 1.11 & 1.05 & 1.93 & 13.57 \\
\hline g9i4s & spruce & SSA & May 27 & -105.113 & 53.998 & 0.62 & 4.36 & 15.0 & 85.0 & 33.37 & 1.66 & 13.43 & 1.04 & 0.99 & 1.73 & 13.32 \\
\hline tf07 & spruce & SSA & May 27 & -105.118 & 53.987 & 0.33 & 3.84 & 2.0 & 85.0 & 33.36 & 2.74 & 14.91 & 0.97 & 0.97 & 2.65 & 14.44 \\
\hline t8t1p & pine & NSA & June 6 & -98.263 & 55.905 & & 1.29 & 8.0 & 140.0 & 51.52 & 3.74 & 19.38 & 1.36 & 1.22 & 5.09 & 23.57 \\
\hline $7 \mathrm{q} 8 \mathrm{t}$ & pine & NSA & June 6 & -98.624 & 55.928 & 0.40 & 1.96 & 6.0 & 100.0 & 33.27 & 6.27 & 22.70 & 0.99 & 0.99 & 6.21 & 22.47 \\
\hline $7 j 0 p$ & pine & SSA & May 31 & 105.051 & 53.883 & 0.46 & 3.94 & 10.0 & 126.0 & 36.63 & 2.30 & 16.27 & 1.17 & 1.08 & 2.68 & 17.54 \\
\hline $67 j 1 \mathrm{p}$ & pine & SA & May 31 & 105.032 & 53.882 & 0.43 & 2.70 & 0.0 & 0.0 & 36.53 & 2.41 & 17.34 & 1.04 & 1.02 & 2.50 & 17.71 \\
\hline g1k9p & pine & SSA & May 27 & -104.748 & 53.909 & 0.36 & 2.51 & 3.5 & 50.0 & 34.36 & 3.31 & 16.21 & 0.98 & 0.98 & 3.25 & 15.82 \\
\hline $\mathrm{g} 4 \mathrm{k} 8 \mathrm{p}$ & pine & SSA & May 27 & -104.764 & 53.919 & 0.37 & 2.68 & 16.0 & 120.0 & 33.44 & 5.65 & 15.38 & 1.10 & 1.05 & 6.24 & 16.12 \\
\hline g7k8p & pine & SSA & May 27 & 104.771 & 53.959 & 0.29 & 2.43 & 0.0 & 0.0 & 34.46 & 3.96 & 16.72 & 0.99 & 0.99 & 3.92 & 16.60 \\
\hline $2 \mathrm{i} 8 \mathrm{p}$ & pine & SSA & May 27 & -105.051 & 54.112 & 0.55 & 5.33 & 3.1 & 70.0 & 34.97 & 2.30 & 14.41 & 1.0 & 0.99 & 2.32 & 14.24 \\
\hline g213t & pine & SSA & May 31 & -104.692 & 53.916 & 0.4 & 2.17 & 0.0 & 0.0 & 39.76 & 4.69 & 15.74 & 1.11 & 1.06 & 5.19 & 16.73 \\
\hline $\mathrm{t} 8 \mathrm{~s} 9 \mathrm{t}$ & young pine & NSA & June 6 & -98.287 & 55.896 & 0.19 & 1.73 & 4.0 & 100.0 & 34.37 & 7.97 & 23.45 & 1.00 & 1.00 & 8.00 & 23.44 \\
\hline f816t & young pine & SSA & June 1 & -104.645 & 53.876 & 0.22 & 2.94 & 5.0 & 100.0 & 49.26 & 3.52 & 18.97 & 1.54 & 1.23 & 5.41 & 23.33 \\
\hline p7v1a & aspen & NSA & June 7 & -98.075 & 55.503 & 0.60 & 2.71 & 9.0 & 20.0 & 37.87 & 2.47 & 30.06 & 0.96 & 0.97 & 2.38 & 29.23 \\
\hline r8v8a & aspen & NSA & June 7 & -97.893 & 55.678 & 0.40 & 3.48 & 10.0 & 30.0 & 37.40 & 3.40 & 24.67 & 0.95 & 0.97 & 3.23 & 23.87 \\
\hline t2q6a & aspen & NSA & June 6 & -98.675 & 55.887 & 0.52 & 2.54 & 6.5 & 90.0 & 33.40 & 2.89 & 30.82 & 0.98 & 0.99 & 2.84 & 30.60 \\
\hline t8s $4 a$ & aspen & NSA & June 6 & -98.370 & 55.919 & 0.29 & 1.97 & 8.0 & 135.0 & 53.49 & 3.31 & 24.35 & 1.41 & 1.13 & 4.68 & 27.62 \\
\hline b9b7a & aspen & SSA & May 31 & -106.187 & 53.591 & 0.52 & 2.67 & 18.5 & 130.0 & 49.98 & 1.38 & 24.47 & 1.48 & 1.16 & 2.04 & 28.29 \\
\hline d619a & aspen & SSA & May 31 & -104.639 & 53.669 & 0.23 & 2.20 & 0.0 & 0.0 & 37.36 & 3.21 & 31.76 & 1.04 & 1.01 & 3.33 & 32.23 \\
\hline d9g4a & aspen & SSA & June 1 & -105.469 & 53.740 & 0.66 & 3.84 & 8.0 & 102.0 & 37.53 & 1.97 & 31.85 & 1.08 & 1.03 & 2.13 & 32.88 \\
\hline
\end{tabular}

The dominant background is sphagnum moss (Sphagnum fuscum), feather moss (Pleurozium schreberi), and labrador tea (Hylocomium splendens) in black spruce (Picea mariana) stands, lichens (Clodonia) and alder (Anlus crispa) in jack pine (Pinus banksiana) stands, and hazelnut (Corylus cornuta) in aspen (Populus tremuloides) stands.

the TM data may be due to this angular difference. However, atmospheric correction and collocation of the site and images may have introduced large errors in the result. It is encouraging that better relationships are obtained from CASI data. One particular point that is confirmed by the CASI results is the decreasing trend of NIR reflectance in response to increasing LAI. Although the same trend was shown by Chen [1996a], it was uncertain because of the variability in the data. The mechanisms controlling this trend are investigated in the following section.

The significance of the relationship between SR and LAI after the BRDF corrections is also improved considerably (Figures 1c and 1f). The main reason for the improvement is the decrease in SR value for NSA stands, which generally have low LAI values. As SR, or NDVI, generally increases with increasing SZA [Leblanc et al., 1997], normalizing to the lower SZA makes SR smaller. The statistical significance of the regression is considerably improved when the background SR value [Miller et al., 1997] is included in the regression. The scatter in the SR and LAI relationship after the BRDF correction is smaller than those in the individual bands because the variability from other sources is also much reduced when the ratio of two correlated bands is taken [Chen, 1996a]. BRDF corrections are worthwhile for determining the SR and LAI relationship be- cause of the significant dependence of SR on solar zenith angle and to a smaller extent on view zenith angle [Leblanc et al., 1997].

The results for jack pine stands are shown in Figures 1a-1f. In general, the effect of BRDF corrections on jack pine stands is much smaller than that on black spruce stands. In the boreal landscape, jack pine stands often have smaller LAI but larger tree crowns than black spruce stands. Because jack pine crowns are relatively large in size and sparse in leaf density, the probabilities of observing shaded foliage on the sunlit side and sunlit foliage on the shaded side are much greater than that for black spruce stands, giving rise to a smaller dependence on view and illumination angles. It is noted that NIR reflectance has the similar decreasing trend to that for black spruce as the LAI increases. Jack pine stands have variable backgrounds depending on the hydrological conditions. When they are found at the top of well-drained hills, the background is usually composed of lichens (Cladina) with low greenness. On the lower part of slopes they usually have abundant green species such as alder shrubs (Alnus). Some relatively wet jack pine stands have considerable green moss cover mixed with lichens. Other herbaceous ground cover types (cranberry, blueberry, etc.) are also found in jack pine stands. Since lichens have different red and NIR reflectances than moss and other green 

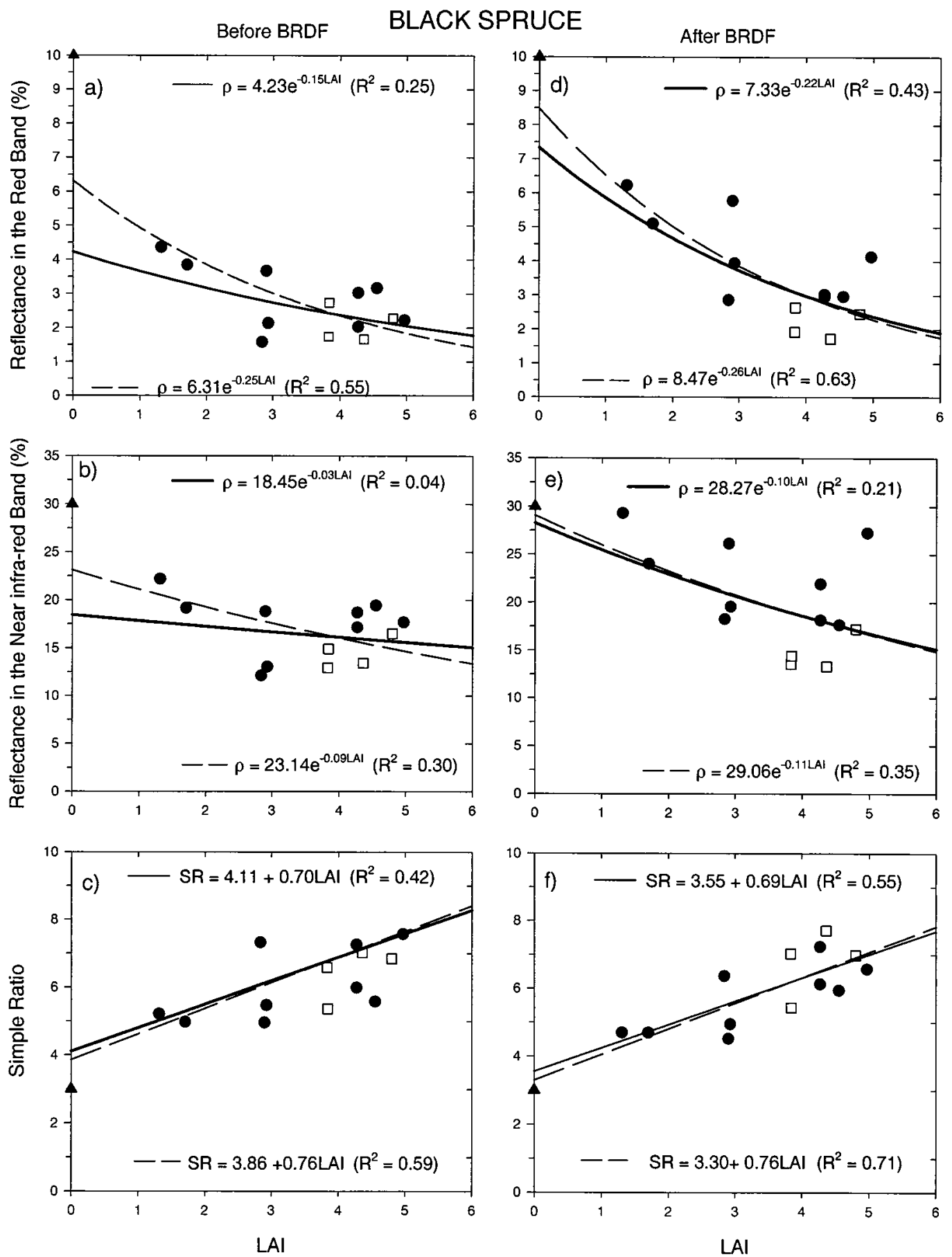

Spruce NSA

ㅁ Spruce SSA

- Understory

- Regression without Understory

- Regression with Understory

Figure 1. (a-f) Red and near-infrared (NIR) reflectances and simple ratio (SR) in response to changes in leaf area index (LAI) for black spruce (Picea mariana) stands before and after bidirectional reflectance distribution function (BRDF) corrections.

cover, the SR and LAI relationship for jack pine is generally noisy. The background noise can be suppressed considerably when mid-infrared data (TM band 5) is used [Brown et al., 1999]. However, the CASI spectrum does not cover the midinfrared wavelengths.

We also include the aspen cover type in this study although the number of sites with both CASI and ground data is mar- ginal for deriving relationships of high statistical significance (Figures 3a-3f). The data are very noisy because of the complexity of aspen stands. Aspen (Populus tremuloides) forest generally has a significant amount of understory vegetation, predominantly hazelnut (Corylus cornuta). The abundance of the understory depends on various site factors, including age, succession history, drainage patterns, etc. Variable understory 


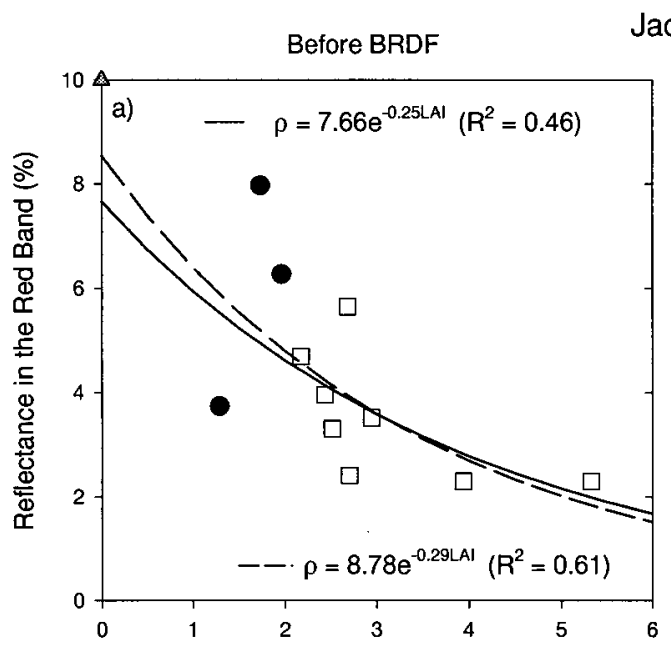

Jack Pine
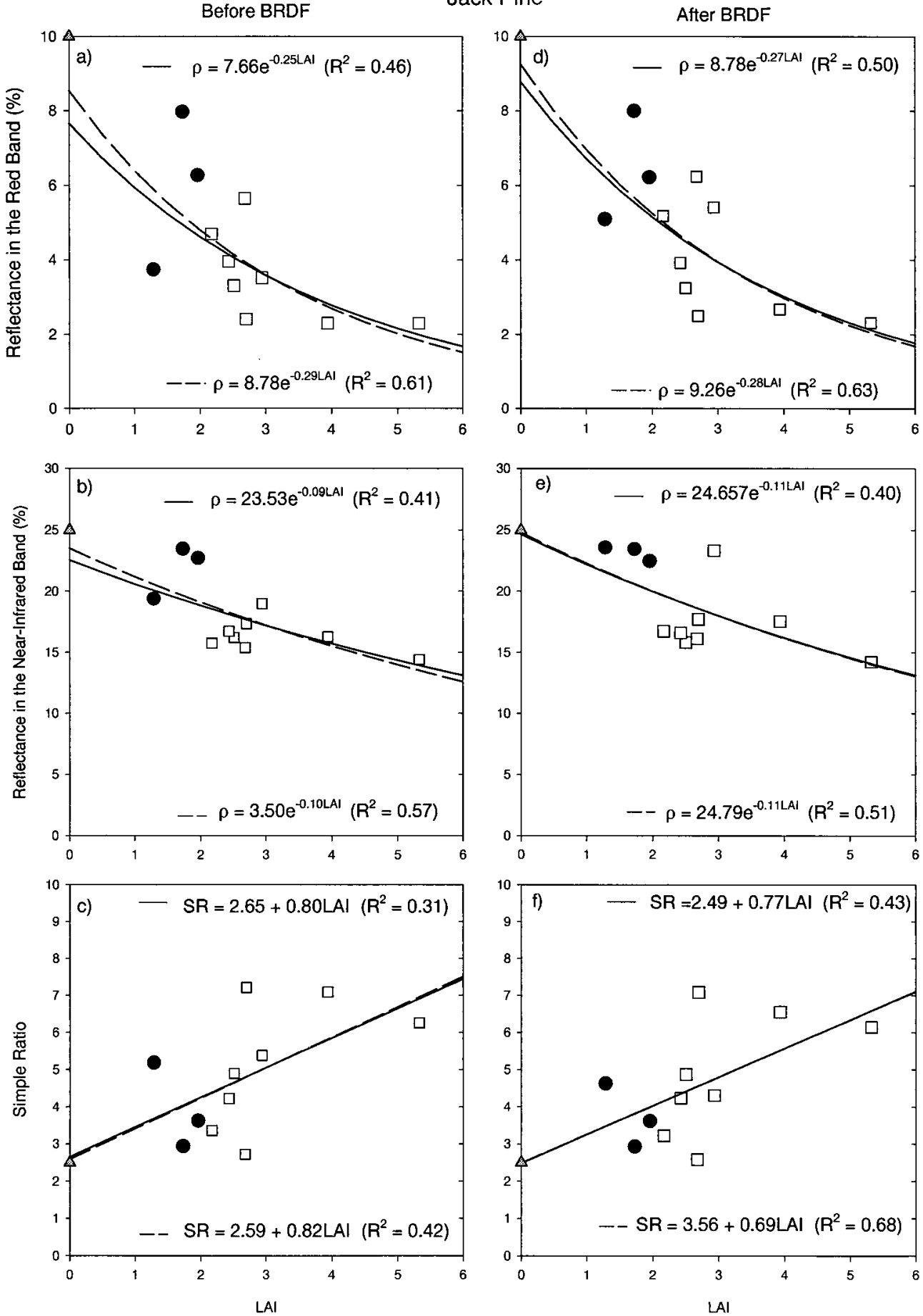

NSA

$\square$ SSA

$\Delta \quad$ Background

- Regression without background

-- Regression with background

Figure 2. (a-f) Red and NIR reflectances and SR in response to changes in LAI for jack pine (Pinus banksiana) stands before and after BRDF corrections.

leaf area, which contributed to the CASI measurements, is the main reason for the large scatter in the various relationships shown in Figure 3. However, some useful information can be obtained: (1) NIR reflectance of aspen species is much higher than those of black spruce and jack pine; (2) SR of aspen stands is also much higher as a result of higher NIR reflec- tance; (3) the trend of NIR reflectance with increasing LAI is not significant but is more likely to be opposite to those of conifer stands, in agreement with Walthall et al. [1997]. Although the small number of data points and the strong understory effect make it difficult to determine the trend, we infer from 4-Scale that the large NIR reflectance of aspen leaves 

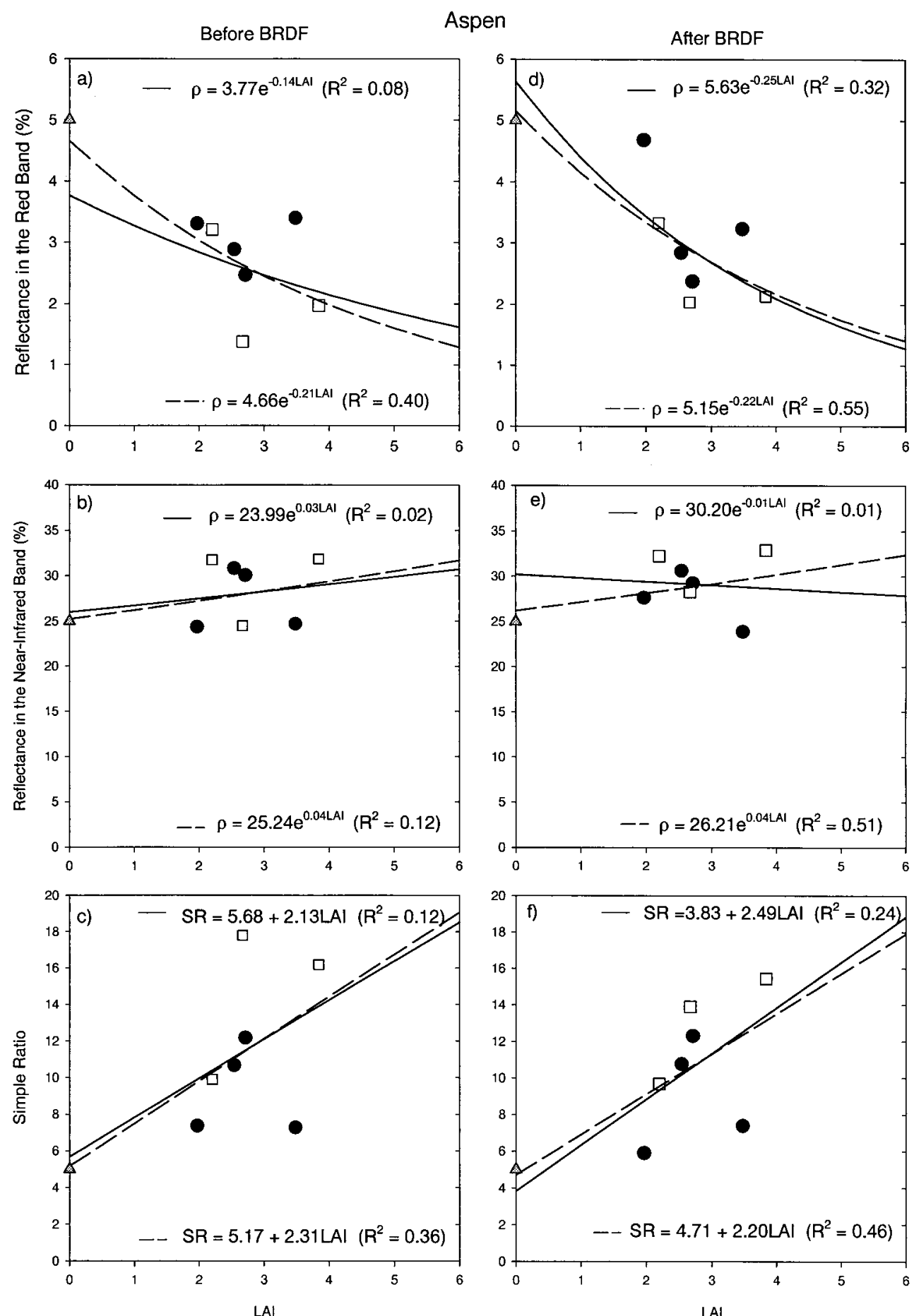

NSA

$\square$ SSA

$\Delta$ Background

- Regression without background

- - Regression with background

Figure 3. (a-f) Red and NIR reflectances and SR in response to changes in LAI for aspen (Populus tremuloides) stands before and after BRDF corrections.

causes strong multiple scattering, which overcomes tree crown shadow effects.

Figures $4 a-4 c$ show the relationships between SR and crown closure (CC) for black spruce, jack pine, and aspen, respectively, after BRDF corrections. The statistical significance for conifer SR-CC relationships is lower than the corresponding
SR-LAI relationships because CC data are less reliable than LAI as a stand average. In auxiliary sites (most of the data points except for seven tower sites), only 11 measurements were taken at each site. While LAI is calculated from the transmittances at five zenith angles covering the hemisphere, $\mathrm{CC}$ is obtained from only the vertical angle range from $0^{\circ}$ to $15^{\circ}$ 

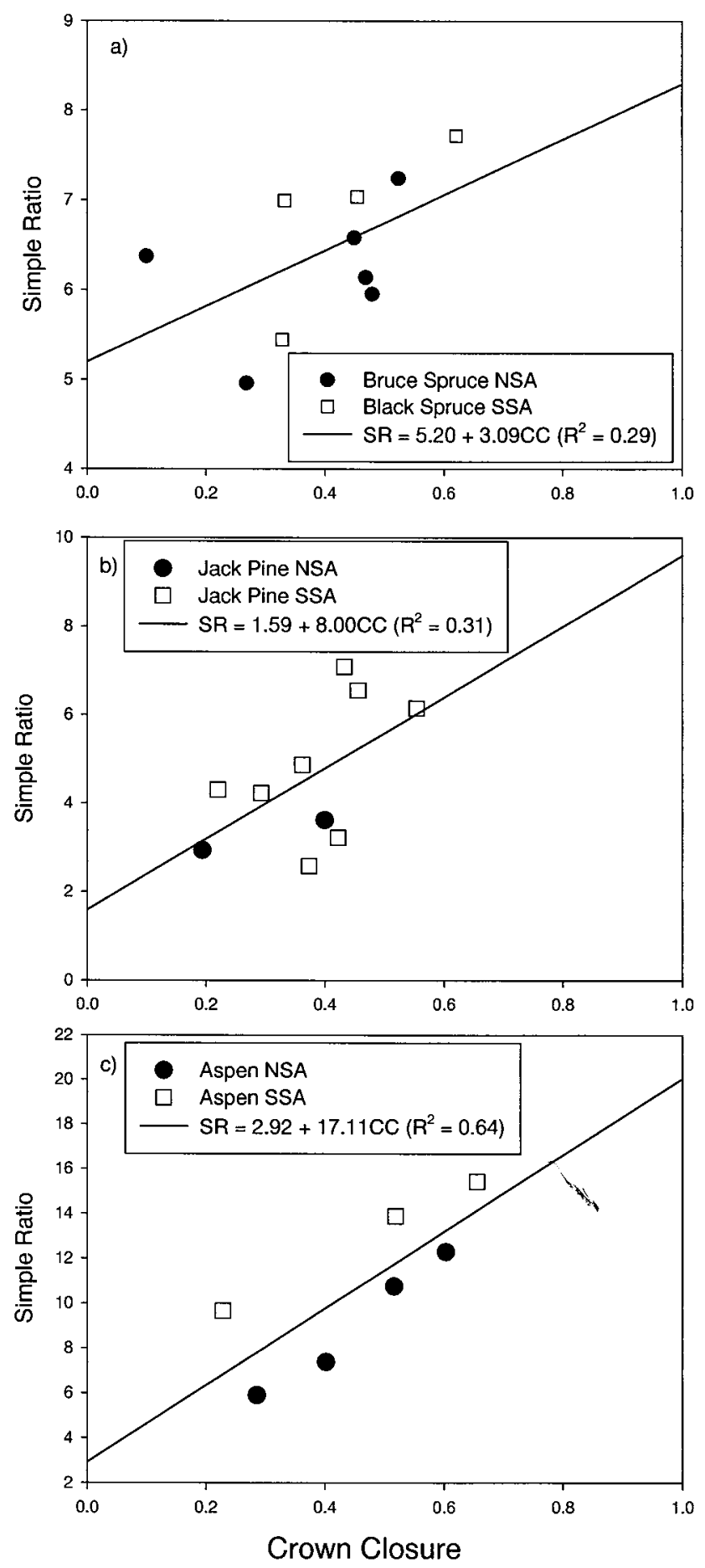

Figure 4. Relationship between SR and crown closure (CC). (a) Black spruce, (b) jack pine, and (c) aspen.

[Chen and Cihlar, 1996]. It is then more variable and has larger measurement errors than LAI. We believe that if good site averages of CC are obtained, CC-SR relationship would be better than LAI-SR relationship because the vertical view is more affected by the CC than by LAI. For aspen the SR-CC relationship is better than the SR-LAI relationship. The value of $R^{2}$ as a measure of statistical significance may not be meaningful in this case because of the small number of sites used in the analysis.

\subsection{Effect of Canopy Architecture on Optical Signals} From Boreal Forests

The trend of decreasing NIR reflectance with increasing LAI apparently runs opposite to predictions using existing canopy reflectance theory: plant leaves have higher NIR reflectance than the background, and increasing LAI should therefore result in an increase in NIR reflectance. This increasing trend has been repeatedly found in agricultural crops [Holben et al., 1980; Martin and Heilman, 1986; Shibayama and Akiyama, 1989; Wiegand et al., 1992; Price and Bausch, 1995]. The behavior of optical signals from black spruce forests, a prevailing boreal species, is investigated using the 4-Scale model. The critical inputs to the model for the investigation are the optical properties of the foliage and the background. Figure 5 shows reflectance spectra for black spruce needles in late spring reported by Middleton et al. [1997] and the background in late spring and midsummer. The needle spectrum is given here as the mean of 1-4 year old needles on both adaxial and abaxial sides for IFC-1. The late-spring background spectrum is the mean of about 40 spectra measured along a $300 \mathrm{~m}$ transect in the Old Black Spruce Tower site in SSA [Miller et al., 1997]. The midsummer spectrum is the mean of over 100 spectra obtained in 1996 from seven black spruce sites in both SSA and NSA using a new spectroradiometer (analytical spectral devices, Boulder, Colorado) following the same measurement and calibration procedure as described by Miller et al. [1997]. The background spectra resemble that of green leaves because the background is mainly composed of green moss and herbaceous understory, but the amplitude of the variation from visible to NIR is considerably smaller than that in the needle spectrum. This is because other ground cover, such as lichens and plant litter, are much less green. The spectrum of open water bodies, which frequently exist in black spruce forests, has not been included. Otherwise the variation in the background spectra would be dampened by a few percent. The background reflectance in the visible region is reduced considerably from spring to summer because of the development of the understory. These spectral measurements provide good basis for understanding the CASI measurements in relation to LAI.

To avoid any complexity that may hinder understanding the

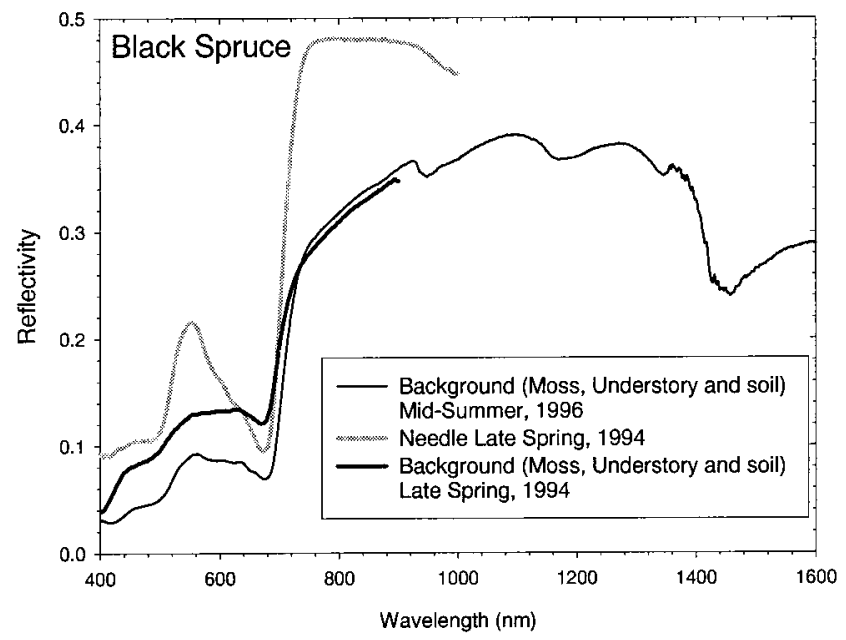

Figure 5. Comparison of reflectance spectra for black spruce needles [Middleton et al., 1997] and for the background (moss, understory, and soil) in black spruce stands measured in latespring 1994 [Miller et al., 1997] and in midsummer 1996. 
processes investigated by the model, we conducted model simulations for only two extreme cases: (1) LAI increases by adding trees of equal leaf area and (2) LAI increases by adding leaf area to trees that grow in proportion with leaf area, so the number of stems remains the same. In reality, forest LAI changes with a combination of these two extreme conditions. The mean of these two simulations may resemble reality. Figure 6 shows 4-Scale model simulations for these two cases in both red and NIR bands. The red/NIR reflectivities used in the simulations are $0.09 / 0.47$ and $0.10 / 0.30$ for the foliage and the background, respectively, according to Figure 5. The red reflectivity for the background is adjusted to 0.10 from 0.12 because the difference between spring and summer appears to be too large according to reliable broadband $(0.4-0.7 \mu \mathrm{m})$ measurements [Chen, 1996b]. The simulations are extended to LAI $=10$ in order to illustrate the patterns of variation in the full possible range for both boreal and temperate conifer forests in general. The difference between these two extreme cases is not very large, because the main factor affecting the reflectances is the gap fraction, which varies similarly with LAI in these two cases. The red reflectance decreases monotonically as LAI increases, as expected. However, the extent of the simulated decrease is smaller than that exhibited in the mea-
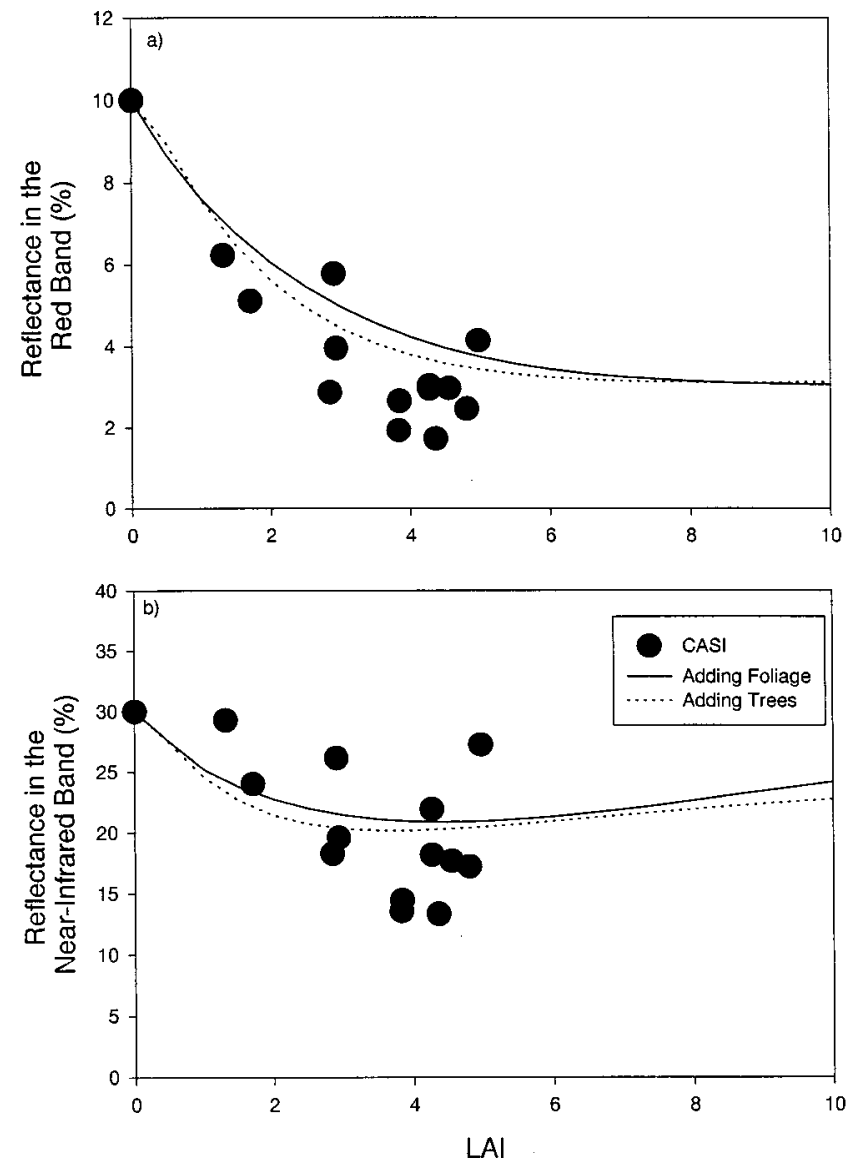

Figure 6. The 4-Scale model interpretation of (a) CASI red and (b) NIR reflectances within and beyond the measured LAI ranges. Two extreme cases are employed in the model simulation: (1) LAI increases by adding trees of the same leaf area and (2) LAI increases by growing tree size in proportion to LAI to keep leaf area density inside the tree crown the same. Reality is expected to be between these two extreme cases.

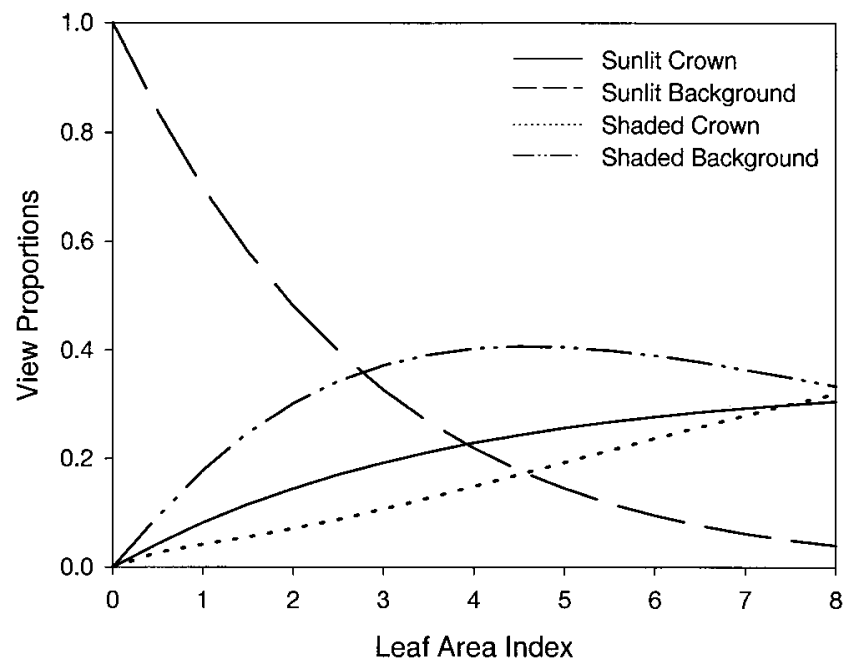

Figure 7. The 4-Scale-simulated scene components as LAI increases, taken as the average of the two extreme cases shown in Figure 6.

sured data. The probability of observing shaded foliage on the sunlit tree crowns considered in the model has helped reduce the modeled red reflectance at large LAI values to a realistic range, otherwise the modeled values would be even larger. We believe that the main reason for the discrepancy between modeled and measured red reflectances at large LAI values is the variation of the background reflectance. The fixed background red reflectance seems to be appropriate for the low LAI stands located in NSA but may not be appropriate for high LAI stands located mostly in SSA. Another source for the discrepancy may come from tree height variation, which creates more mutual shadowing than the simulations by the model. The modeled NIR reflectance in both cases shows an initial steep decrease with increasing LAI. The decreasing trend weakens as LAI increases and is reversed slowly after a critical LAI value of about 4 . Both the tree-adding and the leaf-adding processes reduce the distance between tree outer surfaces, causing more between-crown multiple scattering that is captured by the 4-Scale model. The increase in multiple scattering is the main cause for the increase in NIR at high LAI values. Within the practical range for boreal forests, only the decreasing trend is significant.

To assist in the understanding of the similar but different responses in red and near-infrared bands, the modeled scene components are shown in Figure 7. Although the model is complex, the physical reasons controlling the reflectances in response to LAI changes are simple. The main reason for the initial steep decrease in NIR reflectance is the large decrease in the sunlit background and the simultaneous increase in shadowed background and crown fractions when either more trees are added or the trees grow in size. Because these shadows have much lower reflected radiance than the sunlit counterparts, increasing LAI therefore results in a decrease in NIR reflectance. This shadow effect overcomes the small difference in NIR reflectance between the foliage and the background for open forests until a balance between these two processes occurs at a critical LAI value. After this critical value, the trend is reversed as the observed ground shadow fraction continues to decrease and the sunlit crown fraction continues to increase slowly. As the outer crown edges get closer at high LAI values, 


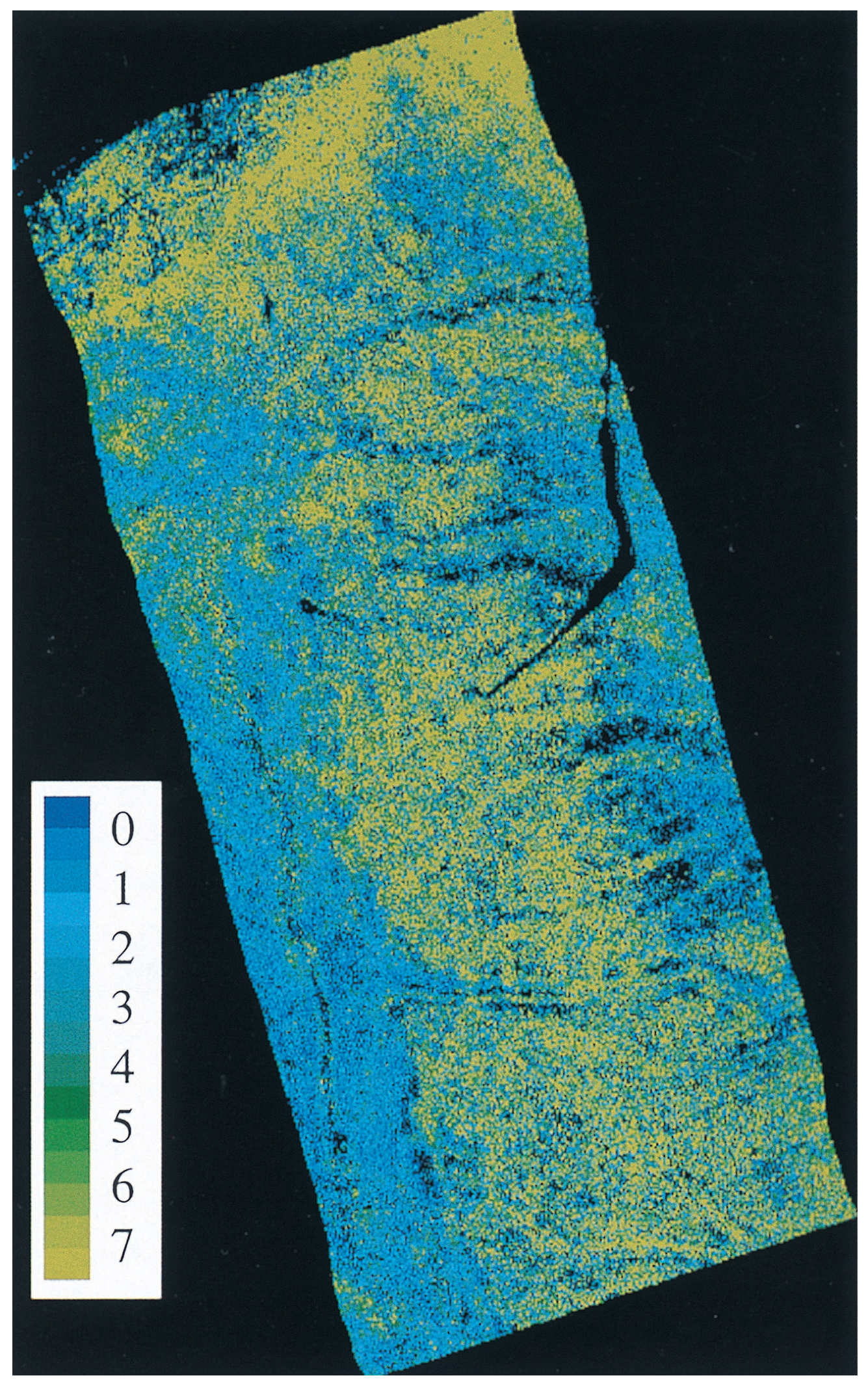

Plate 1. CASI LAI image of a black spruce stand, BOREAS tower site SOBS, located near Candle Lake, Saskatchewan, Canada. The image is obtained after several steps of image processing (see text) based on a SR-LAI relationship derived using transect measurements at the same site. 
multiple scattering may overcome the shadow effects. The same shadow effects also operate in the red band and enhance the decreasing trend with increasing LAI, as given by the spectral difference between the foliage and the background. It is noted that such variation in NIR with LAI may not be obtained with other models without detailed consideration of the interaction of radiation with the canopy architecture at various scales. In particular, the ability of the model to simulate the shadows on the sunlit side of tree crowns is essential for simulations confined to using spectral measurements of needles and the background. An important outcome of the model is that as the LAI increases the relative magnitude of the decrease in red reflectance is much larger than that in NIR, giving rise to the increase in SR with LAI. The difference in optical properties between tree leaves and the background and the different shadow/scattering effects in red and NIR bands are the two main reasons for the success of information retrieval using vegetation indices. However, the useful signals are weak and fragile. Any excessive manipulation of the individual bands in the formulation of various vegetation indices can cause loss of the useful signal. Taking the ratio between the two bands is a useful way to reduce the noise level in the data [Chen, 1996a]. It is demonstrated therefore that shadows created by the structures of forest canopies can drastically alter the behavior of remote sensing signals in the NIR band from the familiar patterns obtained from agricultural crops, where leaves are more or less randomly distributed in space and no significant shadows of large structures exist. This also implies that applications of turbid-medium models to the globe can be very inaccurate for conifer forests at least.

Similar 4-Scale simulations were made for jack pine and aspen, though not shown here. The same red and NIR behaviors discussed above for black spruce are applicable to jack pine. The simulations for aspen stands show an initial slow increase in NIR reflectance, but the increase become larger at higher LAI values. It appears that the strong multiple scattering in aspen sites due to the large leaf NIR reflectance overcomes the shadow effect in the full range of LAI.

The simulation results also qualitatively agree with the findings of Peterson et al. [1987] and Spanner et al. [1990] for temperate conifer forests. Peterson et al. found a weak decrease in NIR reflectance with LAI increasing from 0.5 to 16 , but the trend is insignificant compared with the data scatter. They claimed that the shape of conifer needles and the bark of boles and branches may be responsible for the decrease. Spanner et al. found a general decreasing trend of reflected NIR radiance with LAI from 0.5 to about 4 , and then the trend was reversed after LAI was larger than 4. Groups of data points were widely scattered depending on the age and the openness of the forests. They concluded that canopy closure and background (understory and soil) had effects on the response of reflected NIR radiance to LAI changes. While this conclusion is correct, we believe that the shadow fractions in the forests are the key to understanding the underlying trend of variation. The variability in NIR signals is indeed modified greatly by the background brightness which needs to be considered carefully in LAI algorithm development [Brown et al., 1999].

\subsection{LAI Distribution Around a Black Spruce Site}

To illustrate how CASI images can be used to map LAI distributions, a sample CASI LAI product is shown here (Plate 1). This image is centered at the eddy-covariance tower in the SSA Old Black Spruce (SOBS) site with a noticeable trail in black leading to the tower from the northeast direction. The tower is located some $25 \mathrm{~m}$ east of the trail end.

The image was acquired May 27, 1994, at 1822 (GMT) at $1675 \mathrm{~m}$ altitude with a swath of $1024 \mathrm{~m}$ and resolution of $2 \times$ $4.4 \mathrm{~m}$. Two bands were used: band $7(659.5-671.5 \mathrm{~nm})$ in the red part of the spectrum and band $13(794.7-804.9 \mathrm{~nm})$ in the near infrared (NIR). The following steps were followed in the subsequent processing: (1) the digital number was converted to radiance using sensor calibration coefficients; (2) the radiance was converted to reflectance using estimated spectral downwelling irradiance after atmospheric corrections; (3) the image was geographically registered using onboard GPS readings and rotated to due south-north direction; (4) it was resampled to $2 \times 2 \mathrm{~m}$ pixels in the south-north direction; (5) a BRDF correction is performed to remove the difference across the scene due to view zenith angle; (6) red and NIR band reflectance images normalized to the nadir view and $35^{\circ}$ solar zenith angle are combined to form a SR image; (7) LAI is calculated from a SR-based algorithm derived from transect measurements within the site. Details of steps 1-4 are found from Gray et al. [1997] and Cosandier et al. [1992]; Steps 5-7 are described here. In step 5 the BRDF correction is made using the 4-Scale model with specific inputs of measured stand attributes, including crown diameter and height, stem density and distribution pattern, mean LAI, etc. (for the values, see Chen and Leblanc [1997]). The illumination and view geometry during the image acquisition was SZA $=33.6^{\circ}, \Phi=85^{\circ}$ and the view zenith angle (VZA) in the range from $-17.5^{\circ}$ in the backward scattering direction to $+17.5^{\circ}$ in the forward scattering direction. The image was acquired near solar noon with the Sun located approximately in the south. The flight line was $5^{\circ}$ off the principal solar plane and the scan line was $85^{\circ}$ from the solar azimuth. With the fixed SZA and the scan direction the relative changes in red and NIR reflectances from nadir along a scan line was modeled. Figure 8 shows BRDF correction factors along the scan line. These factors are obtained as the reciprocals of the relative changes from nadir and normalized to SZA of $35^{\circ}$ to allow cross comparison with data from other sites. At small view zenith angles the modeled red and NIR reflectances decreases with increasing view zenith angle in the view direction perpendicular to the principal solar plane, which is in agreement with multiple angle measurements made by the airborne POLDER sensor over the same site [Leblanc et al., 1999]. To normalize the reflectances to the nadir therefore, larger corrections are needed at greater view zenith angles. The fitted curves shown in Figure 8 are almost symmetrical about the nadir. The slight departure from the symmetry is because the scan line was not exactly perpendicular to the solar azimuth. The variation in red reflectance is larger than that in NIR reflectance because of the stronger multiple scattering in NIR than in red. Multiple scattering increases radiance observed from shaded crowns and ground, reducing the difference between sunlit and shaded components in the canopy and hence the dependence of the total observed radiance on view angle.

In step 6, a SR image normalized to the nadir is produced. After the BRDF corrections are applied to the individual bands, SR on both sides of the image strip is reduced by about $4 \%$ from the center. This reduction is necessary to normalize to the nadir value because as the view zenith angle increases, more foliage and less ground is seen, resulting in an increase in $\mathrm{SR}$, which is approximately proportional to the amount of foliage in view of the sensor. 


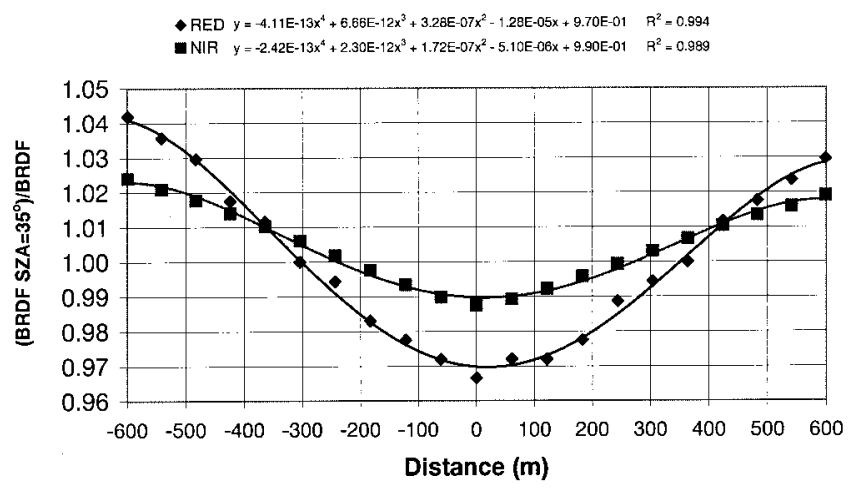

Figure 8. Cross-swath BRDF correction factors calculated using 4-Scale with input of solar zenith angle and flight direction at the time of requisition.

In step 7, the normalized SR image was used to calculate LAI. The SR-LAI algorithm was developed using LAI measurements at the same site only (Figure 9). The measurements were taken at $20 \mathrm{~m}$ intervals along three transects for a total of 53 measurements. All three transects originated from the tower but in different directions. Two transects in the southeast direction were $290 \mathrm{~m}$ long and parallel but separated by $10 \mathrm{~m}$. One transect in the west direction was $490 \mathrm{~m}$ in length. The average of 100 pixels, surrounding each LAI measurement location, was used to determine the SR value for each corresponding ground LAI measurements. Spectral measurements of the background reflectance were used to determine an average background $\mathrm{SR}\left(\mathrm{SR}_{g}=3.65\right)$. By nonlinear regression, we obtained

$$
\mathrm{LAI}=-a \ln \left(1-\frac{\mathrm{SR}-\mathrm{SR}_{g}}{\mathrm{SR}_{s}-\mathrm{SR}_{g}}\right)
$$

where $\mathrm{SR}_{s}=8.0$ taken as the saturated $\mathrm{SR}$ value at $\mathrm{LAI}>10$ and $a=5.4$ determined from the regression. This equation was used to convert SR into LAI on a pixel-by-pixel basis in the CASI image. It is noted that although the SR-LAI relationship appears to be linear for stand averages across large latitudinal ranges with variable background greenness (Figure 1f), the within-stand SR-LAI relationship is more appropriately described using this nonlinear equation. Although the resolution of this LAI image is $2 \mathrm{~m}$, the actual resolution is lower than $2 \mathrm{~m}$ because the original data had a resolution of $2 \times 4.4 \mathrm{~m}$. An average of $3 \times 3$ pixels would be most reliable. The LAI distribution patterns are consistent with the LAI transect measurements, showing decreasing trends in the west and southeast directions. In the calculation, a constant background SR is used, but the measured values along the transects have variations in the range from 2.6 to 4.8 as averages of $4-6$ spectral measurements in each $10 \mathrm{~m} \times 10 \mathrm{~m}$ area. This means that the understory has some undesired contribution to the variations in the overstory LAI images. We investigated possible improvements in the LAI algorithm by using the variable background SR information along the transects. A low $R^{2}$ value of 0.1 was found in the regression of LAI against the difference between the aircraft top-of-canopy and the background SR measurements. It appears that the background greenness does not linearly affect the total remote sensing signals. The amount of tree foliage present in the view from above and the amount of tree shadows on the ground determine the amount of sunlit background exposed to the sensor, which makes the largest contribution to the total reflected radiance from the ground. In the dense part of the forest where the background is less green, the background effect is small. However, in the open part where the background is usually greener if not occupied by open water bodies, the background effect is large. This uneven background effect acts to reduce the variation in the overstory LAI distribution retrieved from SR. In other words, in reality the LAI variations may be larger than what are shown in this LAI image. This effect may be minimized to a small extent in
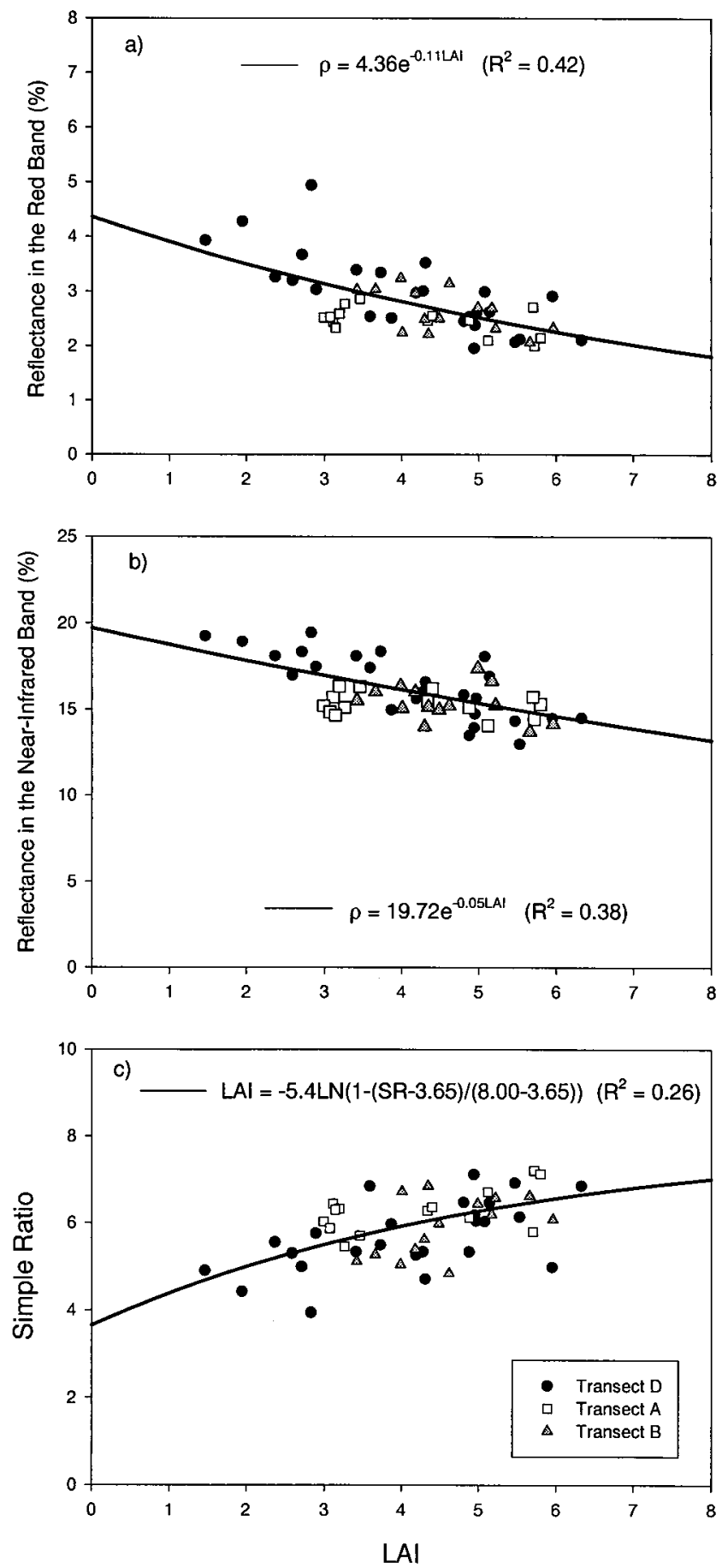

Figure 9. Response of red and NIR reflectances and SR to changes in LAI along three transects in an old black spruce stands (SOBS), near Candle Lake, Saskatchewan, Canada. 
the image processing. From simulations using 4-Scale, we found that SR values are the largest on the shaded side of tree crowns because of the strong multiple scattering in the NIR band. SR for shaded ground is also found to be larger than that of sunlit ground. Therefore we found it preferable to calculate SR on pixel basis and to take the average SR for an area, as opposed to calculating the band averages for an area and then SR from the band averages. In this way, the effect of the shadows on the signal is accentuated and the effect of the background is minimized. It is found from our analysis that these two different ways of obtaining area-averaged SR only makes a $2-3 \%$ difference at low SR values when the probability of obtaining pure sunlit or shadowed pixels is significant but makes no difference at high SR values. The difference is expected to be much larger for images of higher spatial resolution.

Figures $9 \mathrm{a}$ and $9 \mathrm{~b}$ show the patterns of red and NIR variations with LAI, which are in agreement with the findings using the site averages across a large latitudinal range (Table 1), reaffirming the analysis given above for boreal conifer forest in general. The scatter of the data points, however, is much less than that shown in Figure 1. This is because the stand attributes and the background vary in smaller ranges at one site than in large areas.

The LAI image is retrieved using this empirical SR-LAI relationship derived at the same site. This may be a reliable way for fine-resolution LAI mapping. We attempted to use the end member unmixing method developed by Hall et al. [1997] and to relate LAI to one of the end members (sunlit crown, shadows, and sunlit background). No improvements were found with this method because we were not able to separate the total shadows into crown and ground components with only red and NIR channels. Model inversion can be an alternative tool. There are several invertible models developed for this purpose. Some models are applicable to crops and grass canopies [Kuusk, 1995; Gao and Lesht, 1997]. Some models are more useful for forest canopies with explicit considerations of canopy geometrical structure [Rosema et al., 1992; Li and Strahler, 1992]. The Rosema's model is accurate only for very sparse canopies where not significant mutual shadows occurs among tree crowns. Li and Strahler's model includes the mutual shadow effects, but it is difficult to consider multiple scattering in the inversion. A simple and reliable inversion model is yet to be developed for improving LAI mapping from the VI-based methods under various canopy structural and background conditions.

\section{Conclusion}

For quantitative use of airborne remote sensing images, both radiometric and geometric corrections are the necessary steps. After the corrections an improved data set from CASI was obtained for boreal forests. From the data set, one important behavior of NIR reflectance for conifer species emerges: it has a decreasing trend with increasing LAI rather than the increasing trend previously found in agricultural crops. For boreal species of black spruce, jack pine, and aspen, the successful use of vegetation indices, formulated using red and NIR bands, greatly depends on the delicate balance between the reflectance-reducing shadow effects and the reflectanceenhancing multiple-scattering effects in the NIR band, while in the red band, the shadow effects always dominate the signals. In aspen stands, multiple scattering overcomes the shadow effects for the full LAI range, but the variation of NIR reflectance with LAI is small. In black spruce and jack pine stands, the shadow effects are relatively much stronger than the multiple-scattering effects. Because the shadow effects are compensated by the multiple scattering more in NIR than in red, the relative change with LAI in red reflectance is much larger than that in NIR reflectance. Mutual shadowing and multiple scattering are therefore the key processes controlling the behavior of vegetation indices in response to changes in forest biophysical parameters, including LAI, CC, and many others.

Acknowledgments. The senior author would like to thank Mike Sarich and Mario Beauchemin for assistance in image analysis and initial BRDF corrections. We are indebted to Josef Cihlar for useful discussions and support. The project was funded by Canada Centre for Remote Sensing.

\section{References}

Anger, C. D., S. Mah, and S. Babey, Technological enhancements to the Compact Airborne Spectrographic Imager (CASI), in Proceedings of the First International Airborne Remote Sensing Conference and Exhibition, pp. 205-213, Environ. Res. Inst. of Mich., Ann Arbor, 1994

Badhwar, G. D., R. B. MacDonald, and N. C. Metha, Satellite-derived leaf-area-index and vegetation maps as input to global carbon cycle models-A hierarchical approach, Int. J. Remote Sens., 7, 265-281, 1986.

Brown, L. J., J. M. Chen, and S. G. Leblanc, Short wave infrared correction to the simple ratio: An image and model analysis, Remote Sens. Environ., in press, 1999.

Chen, J. M., Evaluation of vegetation indices and a modified simple ratio for boreal applications, Can. J. Remote Sens., 22, 229-242, 1996a.

Chen, J. M., Canopy architecture and remote sensing of the fraction of photosynthetically active radiation absorbed by boreal conifer forests, IEEE Trans. Geosci. Remote Sens., 34, 1353-1368, 1996b.

Chen, J. M., and J. Cihlar, Plant canopy gap size analysis theory for improving optical measurements of leaf area index, Appl. Opt., 34, 6211-6222, 1995.

Chen, J. M., and J. Cihlar, Retrieving leaf area index for boreal conifer forests using Landsat TM images, Remote Sens. Environ., 55, 153$162,1996$.

Chen, J. M., and J. Cihlar, A hotspot function in a simple bidirectional reflectance model for satellite applications, J. Geophys. Res., 102, 25,907-25,913, 1997.

Chen, J. M., and S. G. Leblanc, A 4-Scale bidirectional reflectance model based on canopy architecture, IEEE Trans. Geosci. Remote Sens., 35, 1316-1337, 1997.

Chen, J. M., P. M. Rich, T. S. Gower, J. M. Norman, and S. Plummer, Leaf area index of boreal forests: Theory, techniques, and measurements, J. Geophys. Res., 102, 29,429-29,444, 1997.

Chen, J. M., J. R. Miller, J. Freemantle, S. G. Leblanc, M. Sarich, M. Beauchemin, H. P. White, K. Innanen, and P. Shepherd, Radiometric and geometric analysis of airborne CASI measurements from boreal forests, in Proceedings of 28th CRSS Annual Symposium, Can. Remote Sens. Soc., Calgary, Alberta, Canada, 1998.

Cihlar, J., J. M. Chen, and Z. Li, Seasonal AVHRR composite multichannel data sets for scaling up, J. Geophys. Res., 102, 29,62529,640, 1997.

Cosandier, D., T. Ivanco, and S. Mah, The geocorrection and integration of the Global Positioning System with the Compact Airborne Spectrographic Imager, in Proceedings of the 15th Canadian Symposium on Remote Sensing, pp. 385-390, Can. Remote Sens. Soc., Can. Aeronaut. and Space Inst., Ottawa, Ontario, 1992.

Curran, P. J., and H. D. Williamson, Airborne MSS data to estimate GLAI, Int. J. Remote Sens., 8, 57-74, 1987.

Gao, W., and B. M. Lesht, Model inversion of satellite-measured reflectances for obtaining surface biophysical and bidirectional reflectance characteristics of grassland, Remote Sens. Environ., 59, 461-471, 1997.

Gong, P., R. Pu, and J. Miller, Correlating leaf area index of ponderosa 
pine with hyperspectral CASI data, Can. J. Remote Sens., 18, 275282, 1992.

Gower, S. T., J. G. Vogel, J. M. Norman, C. J. Kucharik, S. J. Steele, and T. K. Stow, Carbon distribution and aboveground net primary productivity in aspen, jack pine, and black spruce stands in Saskatchewan and Manitoba, Canada, J. Geophys. Res., 102, 29,02929,041, 1997.

Gray, L., J. Freemantle, P. Shepherd, J. Miller, J. Harron, and C. Hersom, Characterization and Calibration of the CASI Airborne Imaging Spectrometer for BOREAS, Can. J. Remote Sens., 23, 188195, 1997.

Hall, F., Y. Shimabukuro, and K. Huemmich, Remote sensing of forest structure in boreal stands of Picea mariana using mixture decomposition and geometric reflectance models, Ecol. Appl., 5, 993-1013, 1997.

Holben, B. N., C. J. Tucker, and C. J. Fan, Spectral assessment of soybean leaf area and leaf biomass, Photogramm. Eng. Remote Sens., 46, 651-656, 1980.

Kuusk, A., A fast invertible canopy reflectance model, Remote Sens. Environ., 51, 75-82, 1995.

Leblanc, S. G., J. M. Chen, and J. Cihlar, Directionality of NDVI in boreal forests, A model interpretation of measurements, Can. J. Remote Sens., 23, 369-380, 1997.

Leblanc, S. G., P. Bicheron, J. M. Chen, M. Leroy, and J. Cihlar, Investigation of directional reflectance in boreal forests with an improved 4-Scale model and airborne POLDER data, IEEE Trans. Geosci. Remote Sens., in press, 1999.

$\mathrm{Li}, \mathrm{X}$., and A. H. Strahler, Geometric-optical bidirectional reflectance modeling of the discrete crown vegetation canopy: Effect of crown shape and mutual shadowing, IEEE Trans. Geosci. Remote Sens., 30, 276-292, 1992.

Liu, J., J. M. Chen, J. Cihlar, and W. Park, A process-based boreal ecosystems productivity simulator using remote sensing inputs, $R e$ mote Sens. Environ., 62, 158-175, 1997.

Loechel, S., C. L. Walthall, E. Brown de Colstoun, J. M. Chen, B. L. Markham, and J. Miller, Variability of boreal forest reflectances as measured from a helicopter platform, J. Geophys. Res., 102, 29,49529,494, 1997.

Martin, R. D., Jr., and J. L. Heilman, Spectral reflectance patterns of flooded rice, Photogramm. Eng. Remote Sens., 52, 1885-1890, 1986.

Middleton, E. M., S. S. Chan, R. J. Rusin, and S. K. Mitchell, Optical properties of black spruce and jack pine needles at BOREAS sites in Saskatchewan, Canada, Can. J. Remote Sens., 23, 108-119, 1997.

Miller, J. R., J. Freemantle, P. Shepherd, L. Gray, N. O'Neill, A. Royer, and E. Senese, Development of CASI to meet the needs of BOREAS science, in Proceedings of the 17th Canadian Symposium on Remote Sensing, pp. 169-175, Can. Remote Sens. Soc., Ottawa, Ontario, 1995.

Miller, J. R., et al., Seasonal change in understory reflectance of boreal forests and influence on canopy vegetation indices, J. Geophys. Res., 102, 29,475-29,482, 1997.

Nemani, R., L. Pierce, S. Running, and L. Band, Forest ecosystem processes at the watershed scale: Sensitivity to remotely sensed leaf area index estimates, Int. J. Remote Sens., 14, 2519-2534, 1993.

Neyman, J., On a new class of 'contagious' distribution, applicable in entomology and bacteriology, Ann. Math. Statist., 10, 35-57, 1939.

O'Neill, N. T., A. Royer, and M. N. Nguyen, Scientific and technical report on the development of a modified version of the H5S code which incorporates major features of the $6 \mathrm{~S}$ code, CARTEL Tech. Rep., 1996-020, 62 pp., Cent. d'Appl. et de Rech. en Télédétection, Sherbrooke, Quebec, 1996.
O’Neill, N. T., F. Zagolski, M. Bergeron, A. Royer, J. Miller, and J. Freemantle, Atmospheric correction of CASI images acquired over the BOREAS southern study area, Can. J. Remote Sens., 23, 143-162, 1997.

Peterson, D., M. Spanner, S. Runing, and K. Teuber, Relationship of Thematic Mapper data to leaf area index of temperate coniferous forests, Remote Sens. Environ., 22, 323-341, 1987.

Price, J. C., and W. B. Bausch, Leaf area index estimation from visible and near-infrared reflectance data, Remote Sens. Environ., 52, 5565, 1995.

Rich, P. M., J. Chen, S. J. Sulatycki, R. Vashisht, and W. S. Wachspress, Calculation of leaf area index and other canopy indices from gap fraction: A manual for the LAICALC software, open file report, Kans. Appl. Remote Sens. Program, Lawrence, Kans., 1995.

Rosema, A., W. Verhoef, H. Noorbergen, and J. J. Borgesius, A new forest light interaction model in support of forest monitoring, Remote Sens. Environ., 42, 23-41, 1992.

Sellers, P. J., J. A. Berry, G. J. Collatz, C. B. Field, and F. G. Hall, Canopy reflectance, photosynthesis, and transpiration, III, A reanalysis using improved leaf models and a new canopy integration scheme, Remote Sens. Environ., 42, 187-216, 1992.

Shibayama, M., and T. Akiyama, Seasonal visible, near-infrared and mid-infrared spectra of rice canopies in relation to LAI and aboveground dry phytomass, Remote Sens. Environ., 27, 119-127, 1989.

Spanner, M. A., L. L. Pierce, D. Peterson, and S. W. Running, Remote sensing of temperature coniferous forest leaf area index: The influence of canopy closure, understory vegetation and background reflectance, Int. J. Remote Sens., 11, 95-111, 1990.

Spanner, M. A., L. Johnson, J. Miller, R. McCreight, J. Freemantle, J. Runyon, and P. Gong, Remote sensing of seasonal leaf area index across the Oregon transect, Ecol. Appl., 4, 258-271, 1994.

Walthall, C., S. Loechel, K. Huemmrich, E. Brown de Colstoun, J. Chen, B. Markham, J. Miller, and E. Walter-Shea, Spectral information content of the boreal forest, in Proceedings of the 7th International Symposium on Physical Measurements and Signatures in Remote Sensing, edited by G. Guyot and T. Phulpin, A. A. Balkema, Brookfield, Vt., 1997.

White, H. P., J. R. Miller, and J. M. Chen, Inverse BRDF modeling of BOREAS conifer stands, in Proceedings of IGARSS '98, Inst. of Electr. and Electron. Eng., New York, 1998

Wiegand, C. L., et al., Multisite analysis of spectral-biophysical data of wheat, Remote Sens. Environ., 42, 1-21, 1992.

Wulder, M. A., S. E. Franklin, and M. B. Lavigne, High spatial resolution optical image texture for improved estimation of forest stand leaf area index, Can. J. Remote Sens., 22, 441-449, 1996.

J. M. Chen and S. G. Leblanc, Canada Centre for Remote Sensing, 588 Both Street, Ottawa, Ontario, K1A 0Y7. (jing.chen@ccrs.nrcan.gc.ca). K. A. Innanen, J. R. Miller, and H. P. White, Dept. of Physics and Astronomy, York University, Toronto, Ontario, M3J 1P3.

J. Freemantle, Centre for Research in Earth and Space Technology, Toronto, Ontario, M3J 3K1.

S. E. Loechel, Dept. of Geography, University of Maryland, College Park, MD 20742.

C. L. Walthall, Remote Sensing and Modeling Laboratory, ARSUSDA, Beltsville, MD 20705.

(Received August 25, 1998; revised February 1, 1999; accepted February 8, 1999.) 